
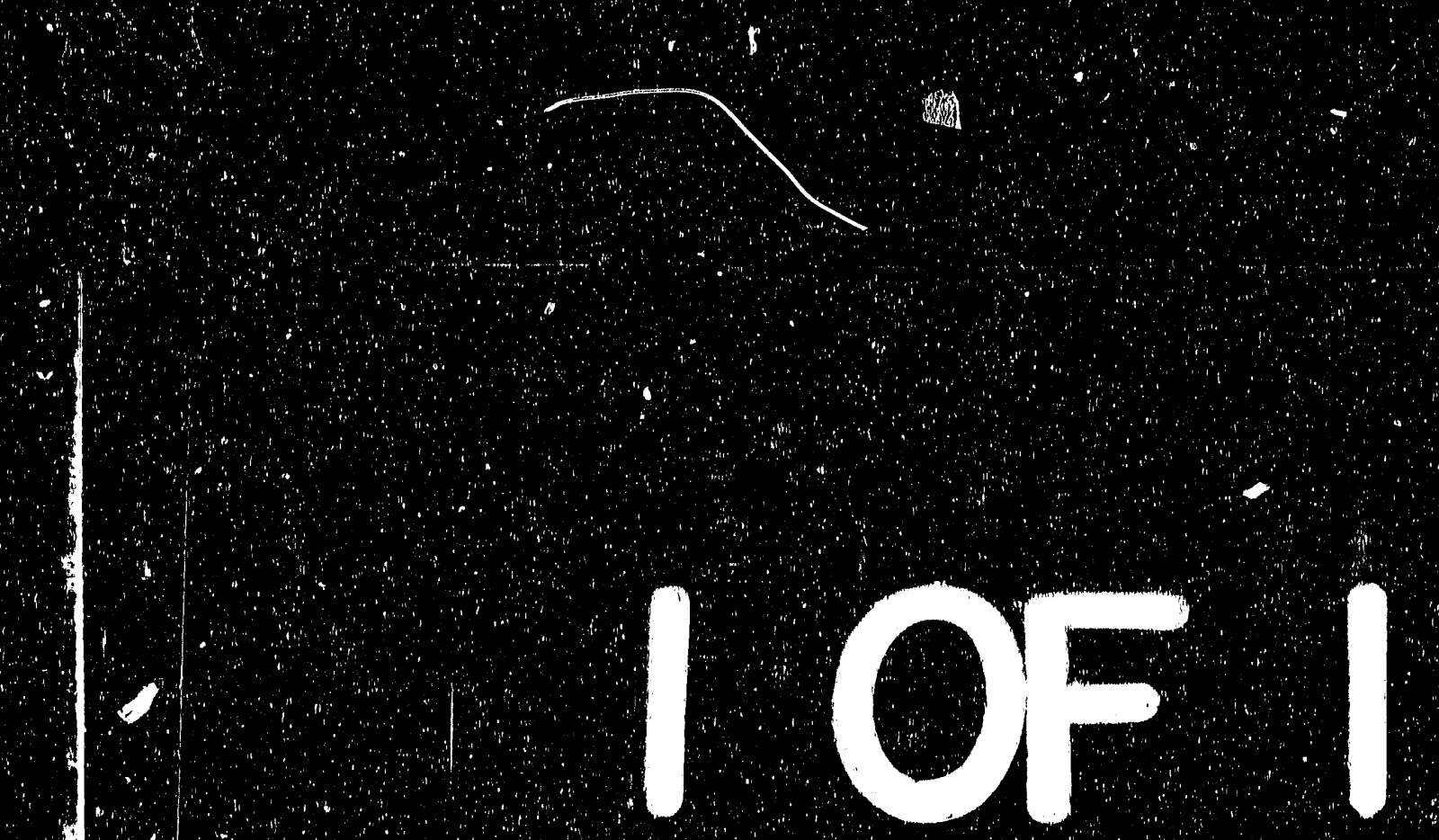

$\therefore$

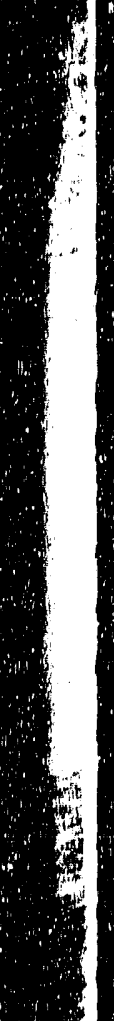

.<smiles>[AsH2]</smiles> 


\section{$\operatorname{Cen} 6-720819--23$}

LBL-32129

UC-404

LB Lawrence Berkeley Laboratory

UNIVERSITY OF CALIFORNIA

\section{Materials Sciences Division \\ National Center for Electron Microscopy}

Presented at the Electron Microscopy Society of America,

Boston, MA, August 16-21, 1992, and to be published in the Proceedings

Determination of the Strain Field from an

HREM Image of a Si Lomer Dislocation

K.-H. Tsai, A.F. Schwartzman, R. Gallego, M. Ortiz, M.A. O'Kerfe, and K.-S. Kim

March 1992
Ron $30 \mathrm{sil}$

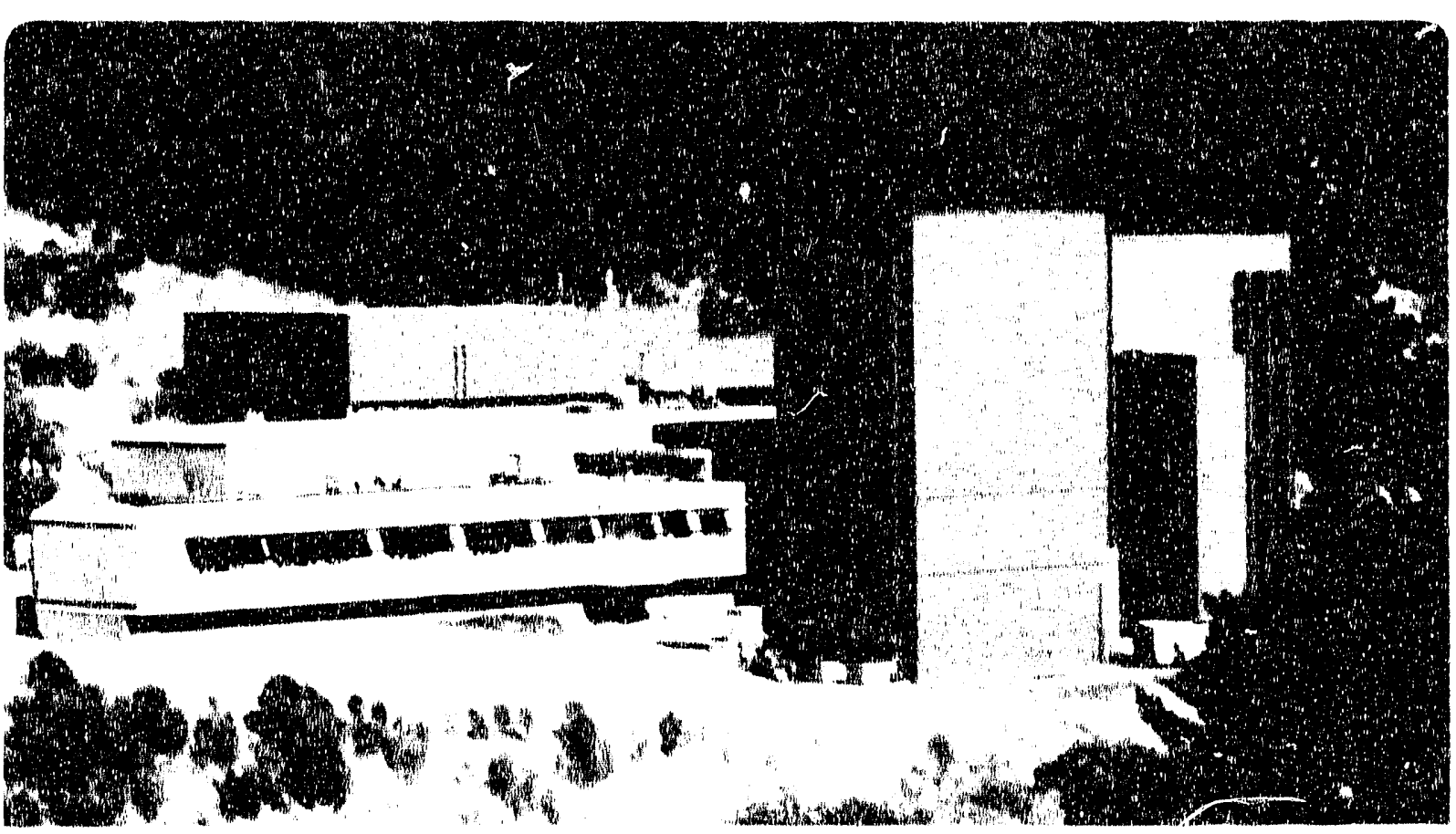

Prepared for tim: 8 is. Department of Energy under Contract Number DE-AC03 76 SF00098

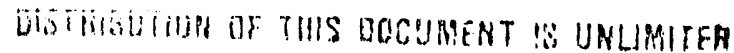




\section{DISCLAIMER}

This docu.nent was prepared as an account of work sponsored by the Unitet States Government. Neither the Linted States Ciovernment nor any agency thereof, nor The Regents of the Lniversity of California, nor any of their employees, makes any warranty', expess or im. plied, or assumes any legal hiability or responsibility for the accuracy, completeness, or usefulness of any infortation, apparatus, product, or process disclosed, or yepresents that its use would not infringe privately owned rights. Reference herein to any specific commercia product, process, or service by its trade name, trademark, manufacturet, or otherwise, does not necessarily constitute og imply its endorsement, recommendation, or favoring by the United States Cov ernment or any agency therew, or The Regents of the Unversity of California. T.e view and opinions of authors expessed herein do $n$. necessarily state or fefled those of the lnited states Government or any agency thereof or the Regenls of the Lindersity of Califorata and shall not be used for advertising or product endorsement purposes.

Lawrence Berkeley Laboratory is an equal opportunity emplo! ax. 


\title{
Determination of the Strain Field from an HREM Image of a Si Lomer Dislocation
}

\author{
K.-H. Tsai*, A.F. Schwartzman*, R. Gallego*, M. Ortiz*, \\ M.A. O'Keefe, \& K.-S. Kim* \\ Materials Science Division \\ National Center for Electron Microscopy \\ Lawrence Berkeley Laboratory \\ University of California, Berkeley, CA 94720 \\ * Brown University \\ Division of Engineering \\ Providence, RI 02912
}

Proc. Joint EMSA/MAS, Boston, MA., 8/16-8/21/92

This work was supported in part by the Office of Naval Research, Grant No. N00014-90. J1295, NSF Grant No. DMR-9002994, and by the Director, Office of Energy Research, Office of Basic Energy Sciences, Materials Science Division of the U.S. Department of Energy' under Contract No. DE-AC03-76SF00098.

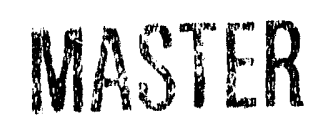

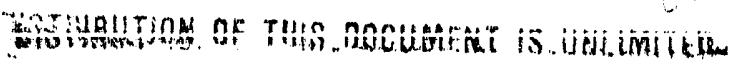




\title{
DETERMINATION OF THE STRAIN FIELD FROM AN HREM IMAGE OF A Si LOMER DISI,OCATION
}

\author{
K.-H. Tsai, A.F. Schwartzman, R. Gallego, M. Ortiz, M.A. O'Keefe* and K.-S. Kim \\ Division of Engineering, Brown University, Providence, RI 02912 \\ *National Center for Electron Microscopy, Materials Sciences Division, Lawrence Berkeley \\ Laboratory, University of California, Berkeley, CA 94720
}

\begin{abstract}
A novel approach to quantitative deformation characterization of high-resolution electron microscopy (HREM) defect images has been developed. The essential principle of this technique, called Computational Fourier Transform Deformation (CFTD) analysis, is to extract an accurate displacement field about a defect from its HREM image using Fourier transformation procedures. The methodology's unique feature is to digitize the defect image and compute the Moire pattern, from which the displacement field is obtained, without the need for an external reference lattice image, normally associated with the interference phenomena. Details of the image processing steps are described elsewhere. ${ }^{1}$ The motivation is that from this data, the displacement gradient can be calculated, which yields much information on the experimenial deformation mechanics of some solid undergoing a specific growth process or mechanical testing. One question that has arisen is whether different imaging conditions of the same defect affects the results of the CFTD analysis. We have studied this problem by analyzing the strain components of simulated images of a Lomer dislocation in Si and present our findings here.
\end{abstract}

The calculation of atom positions about a Lomer dislocation in $\mathrm{Si}$ is based on the minimization of the energy of the atomic lattice, employing the Stillinger-Weber interatomic potential. ${ }^{2}$ The reason for using this potential is that by careful numerical simulations, Stillinger and Weber demonstrated the ability of their potential to accurately replicate a wide range of physical properties of perfect Si. Image simulations were performed at the National Center for Electron Microscopy at Lawrence Berkeley Laboratory using the NCEMSS computer program. The image simulations are for an $80 \AA$ thick crystal in a JEOL JEM-2010 electron microscope operated at $200 \mathrm{kV}$ and equipped with the ARP pole pieces (a $C_{S}$ of $1.0 \mathrm{~mm}$, a Gaussian spread of focus of $70 \AA$, a convergence semi-angle of $0.85 \mathrm{mrad}$ and an objective aperture radius corresponding to $0.6 \AA^{-1}$ ). The results are shown in Figure 1 for a black atom simulation at Scherzer defocus of $-600 \AA$ and a white atom picture at a defocus of $-900 \AA$

Figure 2 shows the results of the strain components analysis of the simulated images by the CFTD method, along with theoretically calculated images based on anisotropic linear elasticity theory. The dynamic range is $\pm 7 \%$. I $r$, previous work, the image prosessing steps produced a noisy background. The artefact has oeen suppressed by filtering the whole domain that lies two Burgers vectors away from the core, using a smoothing function that satisfies the equilibrium and compatibility condition for anisotropic linear elasticity. Within the core region, another nonlinear filter is used to remove random noise. We can see excellent agreement for all the strain components, except $e_{y y}$ inside the core region, between the black and white atom image simulations. Thus, the CFTD analysis is insensitive to the imaging conditions of the electron microscope, except for a field of large strain-gradient such as the dislocation core region. For a large strain-gradient field, the HREM image does not represent the lattice configuration accurately. Moreover, the analysis of the simulated images compares well with the theoretical results. In conclusion, the CFTD analysis continues to be a viable procedure for extracting continuum mechanics information from disciete atomic-resolution images of defects in solids. ${ }^{3}$ 


\section{References}

1. H.C. Choi, A.F. Schwartzman and K.-S. Kim, Thin Films: Stress and Mechanical Properties, Materials Research Society Proc. in press (1992).

2. F.H. Stillinger and T.A. Weber, Phys. Rev. B, 31, 5262 (1985).

3. This work was supported by ONR (N00014-90-J-1295) and the Materials Research Group on Micro-Mechanics of Failure-Resistant Materials at Brown University (NSF grant DMR9002994), and by the Directcr. Office of Energy Research, Office of Easic Energy Sciences, Materials Sciences Division of the U.S. Department of Energy under contract no. DE-AC0376 SF00098 


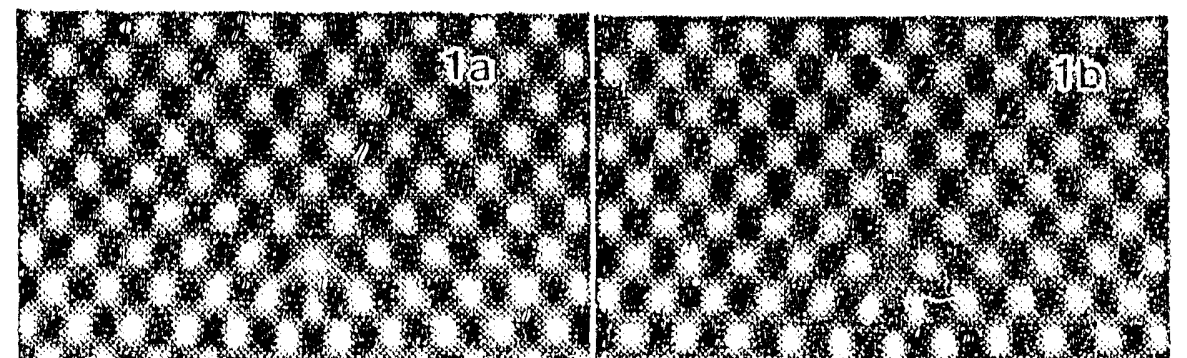

Fig. 1.-.(a) Black and (b) white

aron image simultions of

Bemer dislocation in Si.

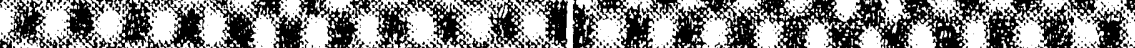

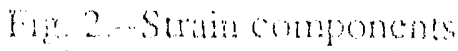

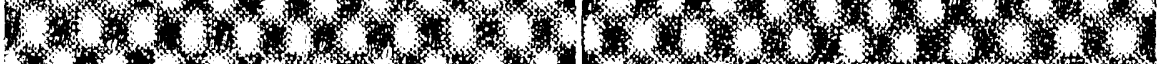

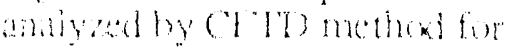

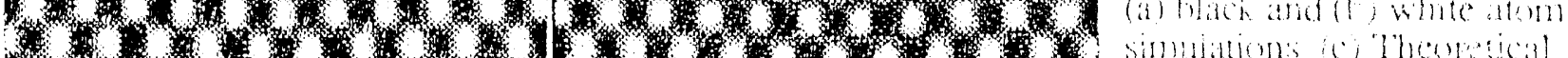

1.

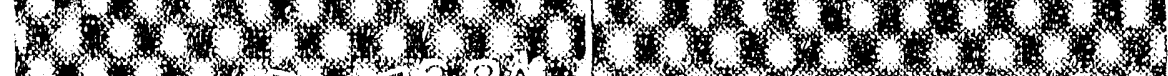
W
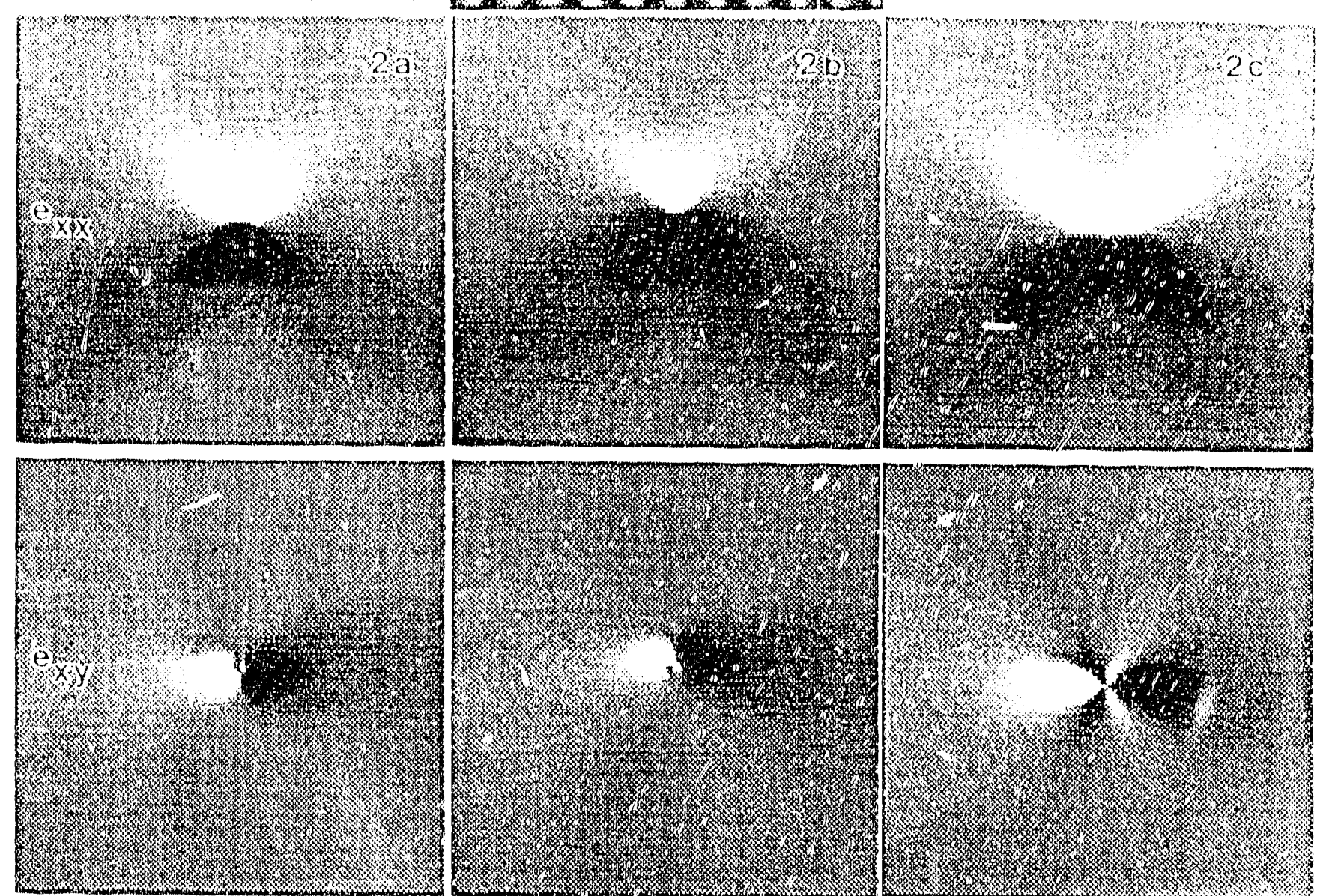

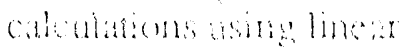

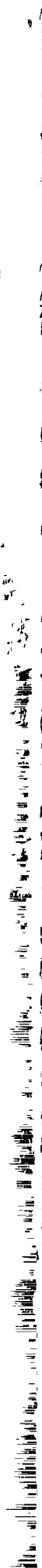

(1)

clastict:
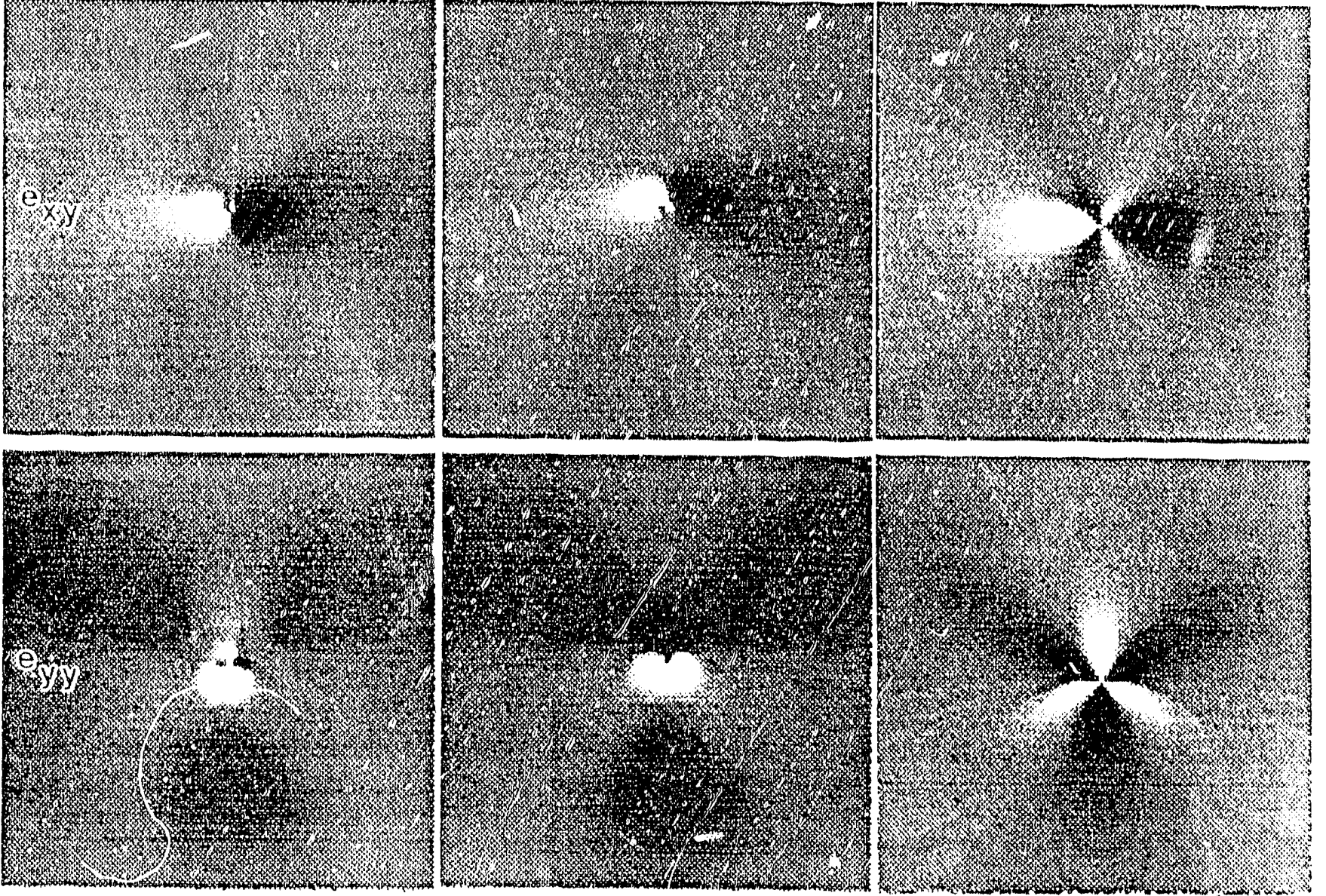

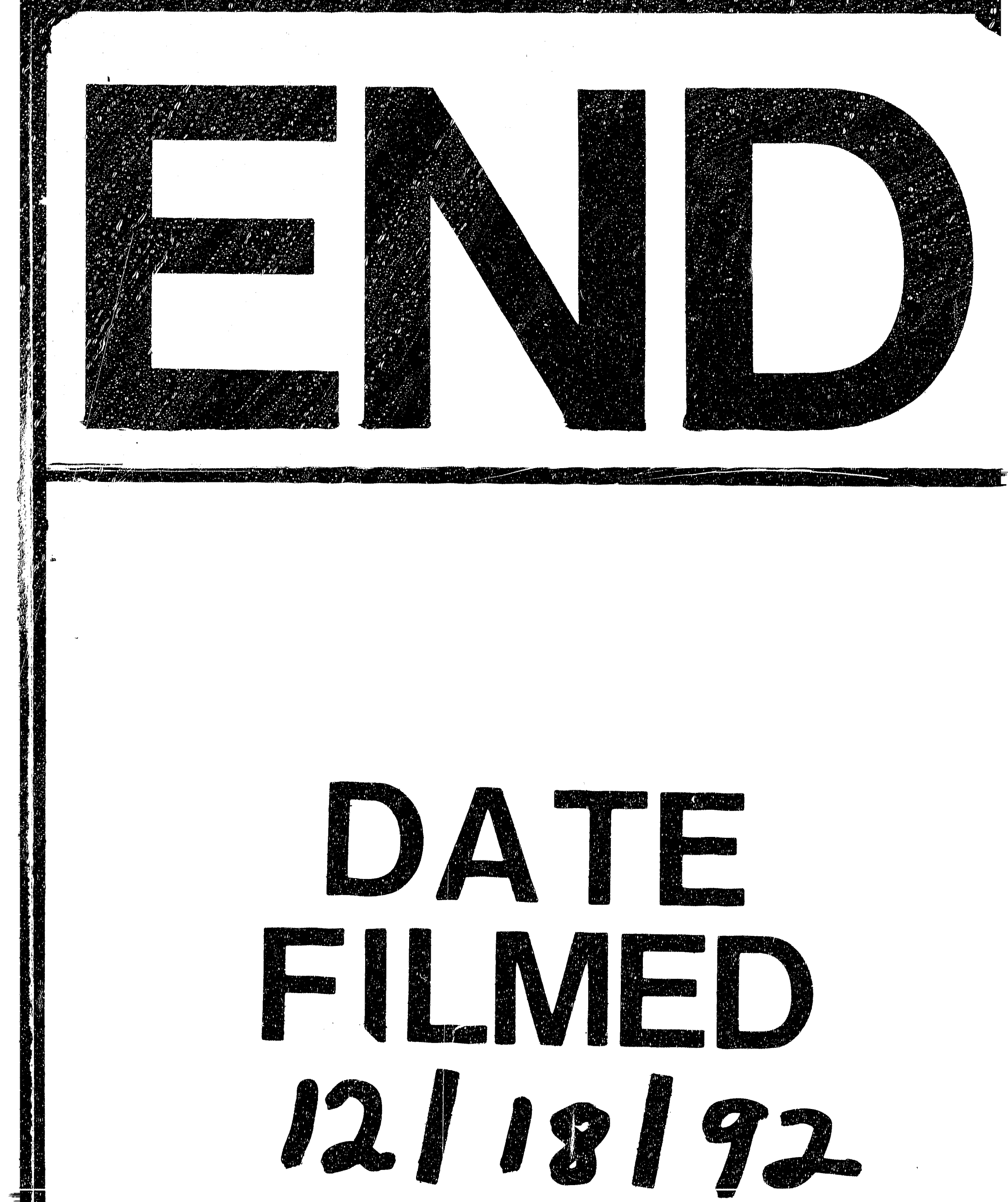

$=$
$\overline{3}$
$=3$ 
